\title{
Gradient Technology for High-Throughput Screening of Interactions between Cells and Nanostructured Materials
}

\author{
Andrew Michelmore, ${ }^{1}$ Lauren Clements, ${ }^{2}$ David A. Steele, ${ }^{1}$ \\ Nicolas H. Voelcker, ${ }^{2}$ and Endre J. Szili ${ }^{1}$ \\ ${ }^{1}$ Mawson Institute, University of South Australia, Mawson Lakes, SA 5095, Australia \\ ${ }^{2}$ School of Chemical and Physical Sciences, Flinders University, Bedford Park, SA 5042, Australia \\ Correspondence should be addressed to Andrew Michelmore, andrew.michelmore@unisa.edu.au
}

Received 28 November 2011; Accepted 21 February 2012

Academic Editor: Krasimir Vasilev

Copyright ( $) 2012$ Andrew Michelmore et al. This is an open access article distributed under the Creative Commons Attribution License, which permits unrestricted use, distribution, and reproduction in any medium, provided the original work is properly cited.

\begin{abstract}
We present a novel substrate suitable for the high-throughput analysis of cell response to variations in surface chemistry and nanotopography. Electrochemical etching was used to produce silicon wafers with nanopores between 10 and $100 \mathrm{~nm}$ in diameter. Over this substrate and flat silicon wafers, a gradient film ranging from hydrocarbon to carboxylic acid plasma polymer was deposited, with the concentration of surface carboxylic acid groups varying between 0.7 and 3\% as measured by XPS. MG63 osteoblast-like cells were then cultured on these substrates and showed greatest cell spreading and adhesion onto porous silicon with a carboxylic acid group concentration between 2-3\%. This method has great potential for high-throughput screening of cell-material interaction with particular relevance to tissue engineering.
\end{abstract}

\section{Introduction}

There are approximately 500,000 bone graft procedures performed in the US alone each year [1]. At an average of around $\$ 35,000$ USA [2], this represents a significant cost per graft. The majority of bone graft procedures use allograft or autograft bone tissues, which can be painful and also have limitations with incompatibility and disease transmission. An alternative approach is the use of engineered bone tissue scaffolds [3]. It has been shown for different cell-types that surface topography can have a major affect on the way cells adhere and proliferate on surfaces [4-8]. It has been hypothesised that the architecture of the cell membrane can change in response to topographical features at the nanoscale, which, in turn, can maximise the cell's attachment to the surface [9, 10]. As cells adhere to their growing surface, stresses are imparted to their cytoskeletal wall, which impacts on their focal adhesion. Although this phenomenon is still not completely understood, it is known that ideally the surface nanotopography should be tuned for each cell type to achieve optimal cell adhesion on synthetic materials.

Ideally, the scaffold should mimic the physical and chemical environment of natural bone tissue, which is mainly composed of a porous hydroxyapatite (HA) and collagen I matrix, to promote optimal osteoblast (bone producing cell) activity leading to bone mineral synthesis/precipitation and integration with the surrounding bone tissue. Nanotextured surfaces have been shown to regulate osteoblast cell growth structure and function [11] and have been used to maintain stem-cell pluripotency and growth [12]. These surfaces typically mimic the structure of extracellular matrix proteins and the basement membrane $(10-300 \mathrm{~nm})$ and hydroxyapatite crystals $(4 \mathrm{~nm})$ [13].

Surface chemistry also plays an important role in regulating osteoblast cellular activity. For example, attachment of osteoblast cells can be controlled by negatively charged surface functional groups [14]. However, the analysis of both nanotopography and surface chemistry in the development of bone engineered tissue scaffolds is both costly and time consuming, limiting the combinations of topography/chemistry that can be analysed. Thin film chemical gradients can be used to investigate cell behaviour [15] whilst maintaining the nanotopography of the surface if the film is thin enough [16].

One method for coating substrates with thin film coatings with functionalised chemistry is plasma polymerisation 
[17]. In this method, a vapour of monomer molecules are electrically excited to form a plasma phase; components of the plasma phase (ions, radicals, and neutrals) then may oligomerise and deposit on any substrate placed in contact with the plasma [18-20]. Through the use of low power and low pressure, functional groups in the monomer may be retained in the final deposited film, for example, carboxylic acid groups from acrylic acid [21]. This method has many advantages over other thin-film coating technologies: the requirements for surface preparation are not stringent, the method relies on an environmentally friendly, solvent-free process conducted at ambient temperature. Furthermore, the plasma deposit forms a pinhole-free, conformal film over the substrate. Plasma polymerisation has been successfully applied to substrates such as 3D scaffolds [22] and microparticles [23]. Gradients of chemical functionality have also been fabricated using this method [24] and can be tailored for investigations into cell behaviour $[16,25]$.

In this paper, a high-throughput platform is demonstrated for analysing cell response to surface chemistry on anodised porous silicon. Gradients of carboxylic acid functional groups were plasma polymerised onto flat and porous silicon with controlled pore geometries between $10 \mathrm{~nm}$ and $100 \mathrm{~nm}$. Following surface characterisation by means of both XPS and AFM, we examined the growth of MG63 osteoblasts on the functionalised nanostructured surfaces.

\section{Experimental}

2.1. Materials. 1,7-octadiene and propionic acid (>98\%) were purchased from Sigma-Aldrich and used as received. $\mathrm{P}^{+}$-type silicon wafers were purchased from Virginia Semiconductors (1-5 $\Omega \mathrm{cm}$ resistivity (100) orientated, boron doped).

2.2. Porous Silicon Preparation. Porous silicon substrates were prepared by the electrochemical anodisation of $\mathrm{p}^{+}$-type silicon [26]. Anodisation was carried out by placing a platinum (Pt) electrode parallel to and $\sim 5 \mathrm{~mm}$ from the silicon surface in a circular Teflon well. Hydrofluoric acid (HF) electrolyte solutions were prepared using $49 \%$ aqueous HF and $100 \%$ ethanol as a surfactant. A $1: 1 \mathrm{HF} /$ ethanol solution was used, applying a current density of $28 \mathrm{~mA} \mathrm{~cm}^{-2}$ for $4 \mathrm{~min}$. Following anodisation, samples were rinsed with ethanol, methanol, acetone, and dichloromethane and subsequently dried under a stream of nitrogen gas.

2.3. Plasma Polymer Deposition. Plasma polymer gradients were deposited onto flat and porous silicon wafers using a previously described method [24]. Briefly, the silicon samples were placed under a mask with a $1 \mathrm{~mm}$ slot. Initially the slot was placed at one end of the porous silicon, a needle valve was opened to allow 1,7-octadiene to flow into the chamber at $1 \mathrm{sccm}$, and the plasma was ignited at $15 \mathrm{~W}$. After $1 \mathrm{~min}$ deposition, the mask was moved $0.25 \mathrm{~mm}$ by an electric motor and the valve was closed slightly to decrease the flow of the monomer into the chamber and at the same time another valve opened slightly to allow propionic acid vapour into the
TABle 1: Peak assignments for XPS analysis of the C1s coreline peaks.

\begin{tabular}{lc}
\hline Functional group & Peak position $(\mathrm{eV})$ \\
\hline $\mathrm{C}-\mathrm{C} / \mathrm{C}-\mathrm{H}$ & 285 \\
$\mathrm{C}-\mathrm{O}$ & 286.5 \\
$\mathrm{C}=\mathrm{O}$ & 287.9 \\
$\mathrm{COOH} / \mathrm{R}$ & 289.2 \\
$\mathrm{C}^{*}-\mathrm{COOH} / \mathrm{R}$ & 285.7 \\
\hline
\end{tabular}

chamber. This process was continued until the end of the silicon sample was reached $(14 \mathrm{~mm})$ at which point the valve connected to the 1,7-octadiene flask was completely closed and only propionic acid vapour was flowing into the chamber at $1 \mathrm{sccm}$.

2.4. X-Ray Photoelectron Spectroscopy. The chemical composition of the plasma polymer deposit was analysed by X-ray photoelectron spectroscopy (XPS) using a SPECS SAGE XPS system with a Phoibos 150 hemispherical analyser at a takeoff angle of $90^{\circ}$ and an MCD-9 detector. The analysis area was circular with a diameter of $0.5 \mathrm{~mm}$. All the results presented here correspond to the use of the $\mathrm{Mg} \mathrm{K} \alpha$ ( $h \nu=$ $1253.6 \mathrm{eV})$, operated at $10 \mathrm{kV}$ and $20 \mathrm{~mA}(200 \mathrm{~W})$. The background pressure was $2 \times 10^{-6} \mathrm{~Pa}$. A pass energy of $100 \mathrm{eV}$ and kinetic energy steps of $0.5 \mathrm{eV}$ were used to obtain wide scan survey spectra, while $20 \mathrm{eV}$ pass energy and energy steps of $0.1 \mathrm{eV}$ were used for the high-resolution spectra of the $\mathrm{C} 1 \mathrm{~s}$ coreline peaks. Survey and C1s spectra were collected at $1 \mathrm{~mm}$ intervals.

Spectra were analysed using CasaXPS (Neil Fairley, UK). A linear background was applied to the $\mathrm{C} 1 \mathrm{~s}$ coreline spectra, and synthetic peaks were applied following Beamson and Briggs [27] as outlined in Table 1. The lineshape and fullwidth-at-half-maximum of the synthetic peaks were kept constant at GL(30) (30\% Lorentzian, 70\% Gaussian) and $1.7 \mathrm{eV}$, respectively. Spectra were charge corrected with respect to the aliphatic carbon peak at $285.0 \mathrm{eV}$.

2.5. Atomic Force Microscopy. An NT-MDT NTEGRA SPM with a $100 \mu \mathrm{m}$ piezo scanner was used to measure the topography of the substrates in noncontact mode. Silicon nitride NT-MDT NSG03 gold-coated tips were used and had a resonance frequency between 65 and $90 \mathrm{kHz}$, and a tip radius of less than $10 \mathrm{~nm}$. The amplitude of oscillation was $10 \mathrm{~nm}$ and all experiments were performed at a scan rate of $1 \mathrm{~Hz}$. The scanner was calibrated in the $x, y$, and $z$ directions using $1.5 \mu \mathrm{m}$ grids with a height of $22 \mathrm{~nm}$.

2.6. MG63 Osteoblast-Like Cell Culture. Immortalised MG63 osteoblast-like cells, derived from an osteosarcoma of human bone with a fibroblast morphology and adherent growth properties, were cultured in Dulbecco's modified Eagle's medium (DMEM) supplemented with $10 \%(\mathrm{v} / \mathrm{v})$ newborn calf serum, 100 units of penicillin, and $100 \mu \mathrm{g}$ of streptomycin under typical cell culture conditions $\left(37^{\circ} \mathrm{C}\right.$ in a humidified $5 \% \mathrm{CO}_{2}$ atmosphere). The cells were dislodged from 


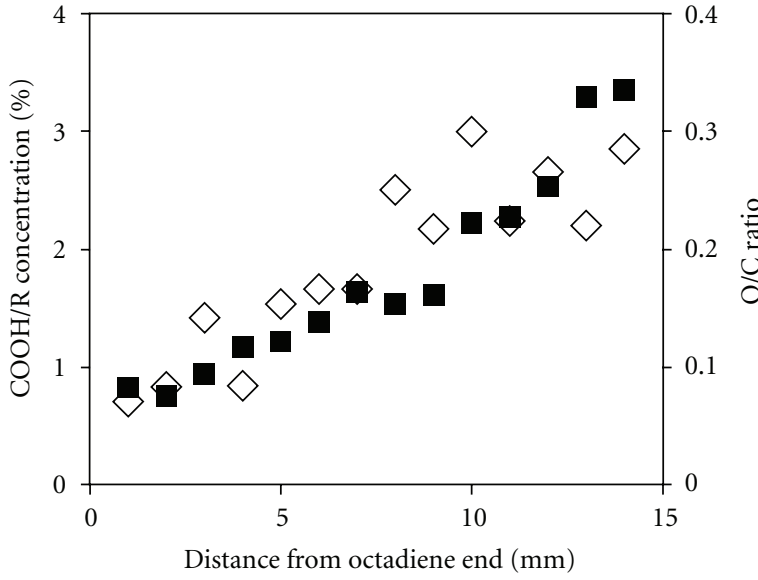

(a)

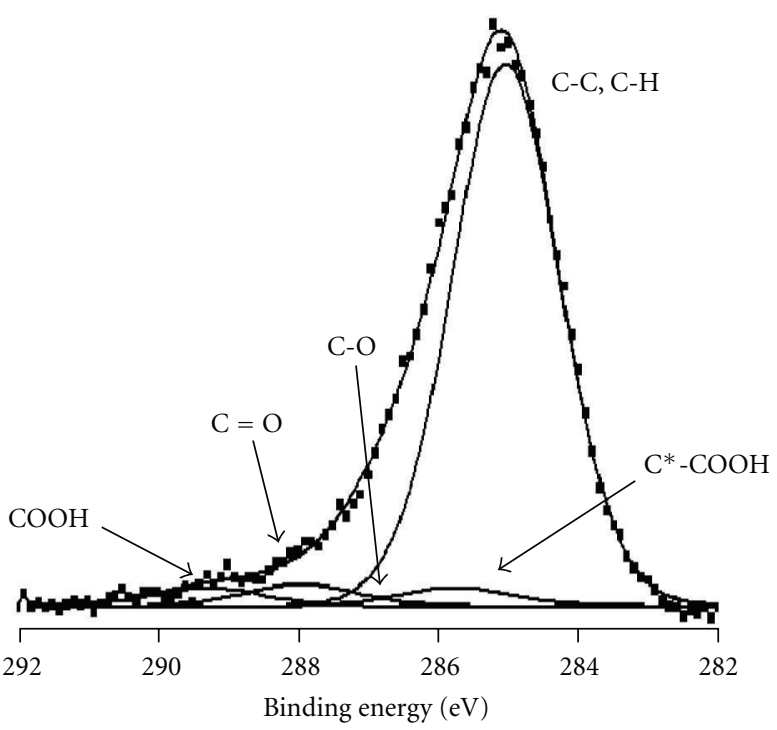

(b)

FIGURE 1: (a) Concentration of COOH/R groups from the C1s coreline XP spectra $(\diamond)$ and the O/C ratio across a silicon substrate coated with a plasma polymer gradient ( $)$. (b) High-resolution scan of the C1s coreline peak at the carboxylic acid rich end of the plasma polymer gradient. The carboxylic acid peak occurs at $289.2 \mathrm{eV}$.

the flasks for passaging and transferred to the test samples with the aid of trypsin. The dilution of cells seeded onto each test sample is given in each figure caption. All cell culture reagents were purchased from Sigma.

2.7. Cell Staining. Cell nuclei were stained with $2 \mathrm{~mL}$ of $0.1 \mathrm{mg} / \mathrm{mL}$ Hoechst 33342 dye (Invitrogen) prepared in PBS ( $\mathrm{pH}$ 7.4) for $30 \mathrm{~min}$. Cell membranes were stained using $2 \mathrm{~mL}$ of $100 \mu \mathrm{M}$ of $\mathrm{DiOC}_{5}$ (3) (Invitrogen). The samples containing the stained cells were then washed twice with $2 \mathrm{~mL}$ of PBS. The cells were then fixed with $1 \mathrm{~mL}$ of formaldehyde (Sigma) and rinsed in Milli-Q water.

2.8. Fluorescence Microscopy. Fluorescence microscopy was carried out using a TE2000 Nikon inverted microscope equipped with a $4 \mathrm{x}$ objective for cell nuclei (Hoechst 33342 stained cells) imaging and through a 20x objective for cell membrane $\left(\operatorname{DiOC}_{5}(3)\right.$ stained cells) imaging. Images of Hoechst 33342 were captured through a Nikon filter with 381-392 nm excitation and 415-570 nm emission, and for $\mathrm{DiOC}_{5}(3)$, through a Nikon filter with $455-485 \mathrm{~nm}$ excitation and 500-545 $\mathrm{nm}$ emission. Images were recorded with a Nikon DXM1200C digital camera and processed using NISElements Basic Research v2.2 software.

\section{Results}

3.1. Surface Characterisation. The surfaces were coated with a chemical gradient ranging from 1,7-octadiene plasma polymer to propionic acid plasma polymer extending over a distance of $14 \mathrm{~mm}$ as shown in Figure 1. The concentration of $\mathrm{COOH} / \mathrm{R}$ groups increased from $0.7 \%$ at one end to $3.0 \%$ at the other of the gradient. The $\mathrm{O} / \mathrm{C}$ ratio increased from 0.07 to 0.34 indicating an increasing degree of oxygen incorporation into the plasma polymer film towards the propionic acid end, consistent with the increasing concentration of $\mathrm{COOH} / \mathrm{R}$ groups.

Survey spectra were performed at all points along the gradient and showed minor peaks for Si $2 s$ and Si $2 p$. This showed that the plasma polymer layer thickness was less than the sampling depth of XPS, at around $10 \mathrm{~nm}$ [28]. This was confirmed by AFM images of points along the gradient, shown in Figure 2. The RMS surface roughness of flat silicon was measured to be less than $0.2 \mathrm{~nm}$, with a maximum peak-peak of less than $1 \mathrm{~nm}$. As expected, the RMS roughness was higher on porous silicon at $0.6 \mathrm{~nm}$, and the maximum peak-peak was also higher at $6 \mathrm{~nm}$. The roughness of the flat and porous silicon surfaces remained unchanged after deposition of the plasma polymer gradient, indicating that the coating was thin and had conformed to the underlying substrate topography.

3.2. Cell Adhesion and Spreading. After incubation with MG63 osteoblast-like cells for $4 \mathrm{~h}$, the cell nuclei and membrane were stained with Hoechst 33342 and $\mathrm{DiOC}_{5}(3)$, respectively. As shown in Figure 3, the cells attached relatively homogeneously to the chemical gradient surface for both flat and porous silicon, with a slightly higher density on porous silicon. This is also shown quantitatively in Figure 4, where after $4 \mathrm{~h}$ of incubation, the cell density was relatively constant across the gradient at an average of $1.5 \times 10^{5}$ cells $/ \mathrm{cm}^{2}$ for porous silicon, and $8 \times 10^{4}$ cells $/ \mathrm{cm}^{2}$ for flat silicon. However, the level of cell spreading was observed to be different across the substrates. At positions 10 and $11 \mathrm{~mm}$ (Figure 5), corresponding to a carboxylic acid concentration of $2-3 \%$, a greater degree of cells spread compared to cells 


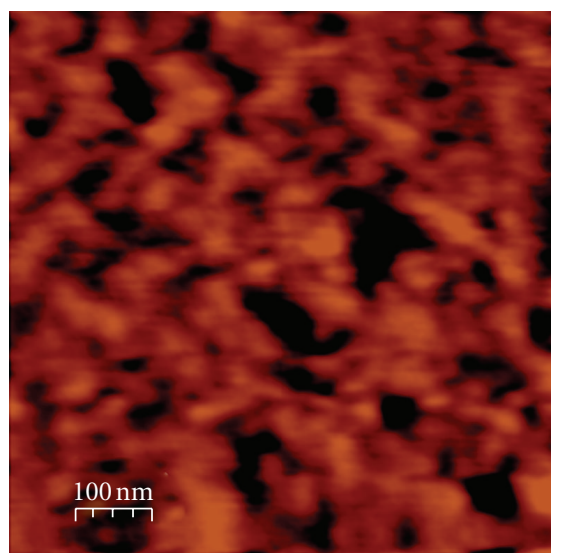

(a)

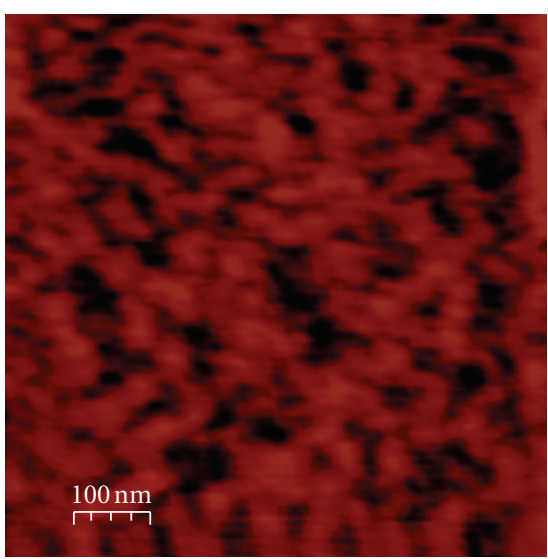

(b)

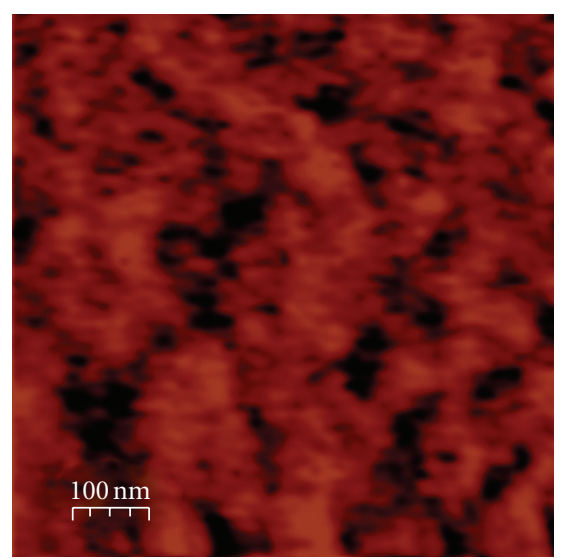

(c)

FIgURE 2: AFM height images of porous silicon coated with a plasma polymer gradient. (a) Hydrocarbon end (position 1 mm). (b) Hydrocarbon/carboxylic acid combined (position $7 \mathrm{~mm}$ ) and (c) carboxylic acid end (position $13 \mathrm{~mm}$ ).

Horizontal distance from hydrocarbon to carboxylic acid end ( $\mathrm{mm}$ )

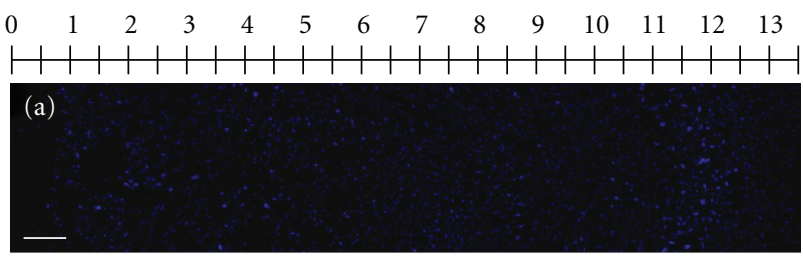

(b)

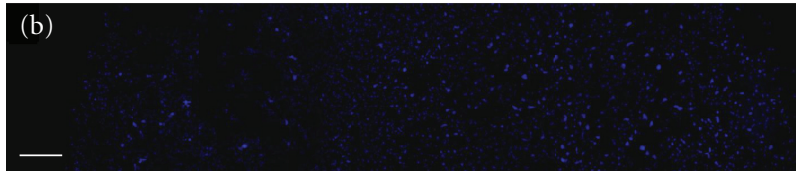

FIGURE 3: Fluorescence micrographs of Hoechst 33342 stained MG63 osteoblast-like cells on plasma polymer chemical gradients of carboxylic acid deposited onto (a) a flat silicon wafer and (b) a porous silicon wafer. Images were recorded after $4 \mathrm{~h}$ of incubation with $7.7 \times 10^{4}$ cells $/ \mathrm{mL}$. Scale bar $=500 \mu \mathrm{m}$.

attached to the substrate outside of this region. Outside of these regions, the cells were rounded and exhibited very little spreading. The attachment of cells is mediated by an intermediate complex proteinaceous layer, which quickly adsorbs to the material (in this case the plasma polymer) before cells reach the surface. It is well known that many of the proteins found in the serum supplement of the cell culture medium contain cell adhesion motifs, such as the arginineglycine-aspartate (RGD) amino acid sequence, which interact with cell surface receptors to facilitate cell attachment. We hypothesise that the strength of protein adsorption was much greater at the hydrophobic (hydrocarbon-rich) end of the chemical gradient compared to the relatively weak interactions at the hydrophilic (carboxylic acid-rich) end. The strong interactions between the protein and the hydrophobic polymer surface may have induced protein denaturation or conformational changes rendering the cell adhesion motif of the proteins inaccessible to the cell surface receptors. In addition, we also note that surface topography significantly influenced the attachment and growth of the cells. Cell spreading was enhanced on the plasma polymer film coated on the nanostructured porous silicon wafer compared to the flat silicon wafer. In Figures 5(a)-5(d), the cells were rounded and showed some degree of spreading on flat silicon. For images (e)-(h) on porous silicon however, the cells were more elongated and showed a higher degree of spreading.

After a further $20 \mathrm{~h}$ of incubation, the substrates were washed to remove rounded and loosely bound cells from the substrate surface. At the hydrocarbon-rich end of the gradient, most of the cells were easily removed from both flat and porous silicon wafers. However, in the region with $2-3 \%$ carboxylic acid groups, many cells remained on the surface, resulting in a gradient of cell density as shown in Figure 6. As shown in Figure 4, the cell density was higher on porous silicon compared to flat silicon. The maximum cell density of approximately $5 \times 10^{5}$ cells $/ \mathrm{cm}^{2}$ occurred at position $11 \mathrm{~mm}$, corresponding to a carboxylic acid concentration of $2.6 \%$.

\section{Discussion}

4.1. Topography. It has previously been shown that topography on the nanoscale can affect cellular attachment. For example, Suh et al. [29] showed that micron-scale pits in titanium substrates enhanced early osteoblast attachment and proliferation. Substrates with smaller pores have also been studied [7]. Pores approximately $170 \mathrm{~nm}$ in diameter and $14 \mathrm{~nm}$ deep doubled cell adhesion of osteoblast cells compared to flat surfaces, but larger and deeper pores exhibited less of an effect. The results presented here show an increase in osteoblast attachment on porous silicon substrates compared to flat substrates, in agreement with these previous studies.

These results indicate that surface roughness and nanotopography can promote cell adhesion and growth. There is probably a value of surface roughness that is ideal for promoting cell adhesion. Determining this ideal level using standard techniques would involve preparing a large number of samples. An alternate approach has been demonstrated by others, where cells were cultured on porosity gradients 


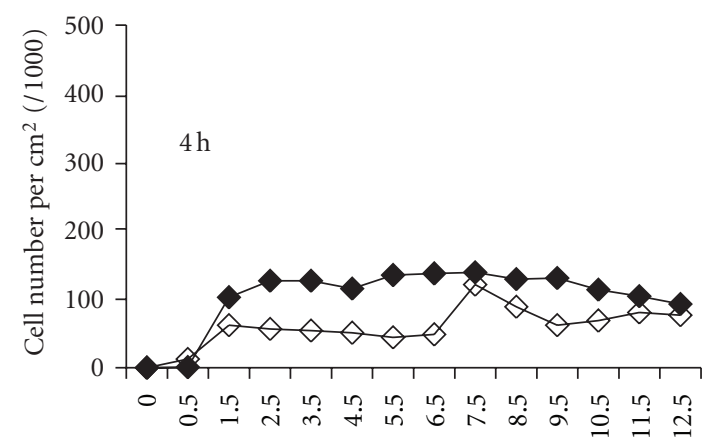

Distance from octadiene end $(\mathrm{mm})$

(a)

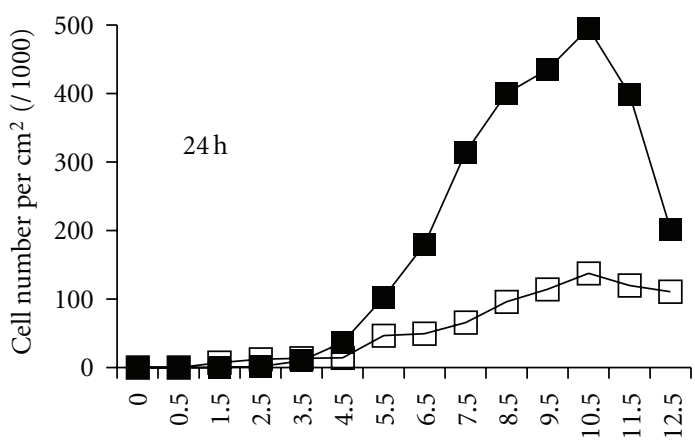

Distance from octadiene end $(\mathrm{mm})$

(b)

FIgURE 4: Cell density on flat (open symbols) and porous silicon (closed symbols) after $4 \mathrm{~h}$ incubation (a) and $24 \mathrm{~h}$ incubation (b).

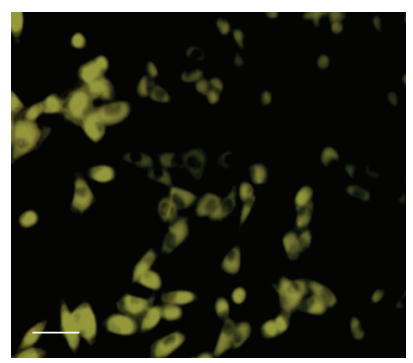

(a)

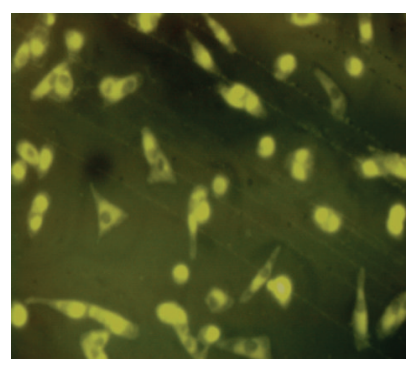

(e)

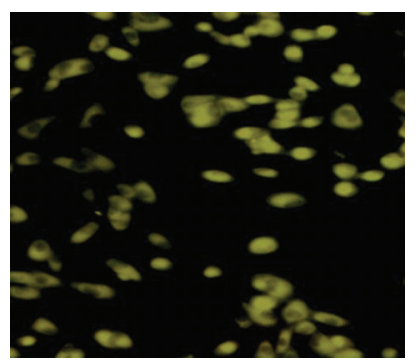

(b)

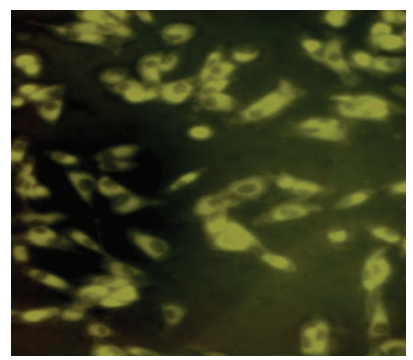

(f)

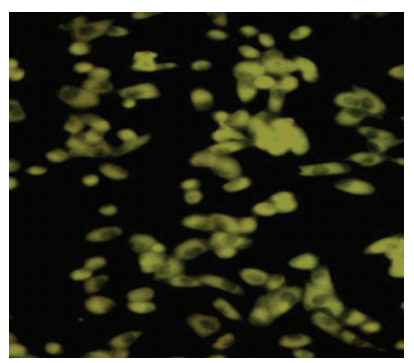

(c)

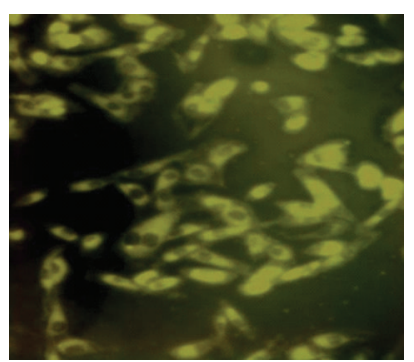

(g)

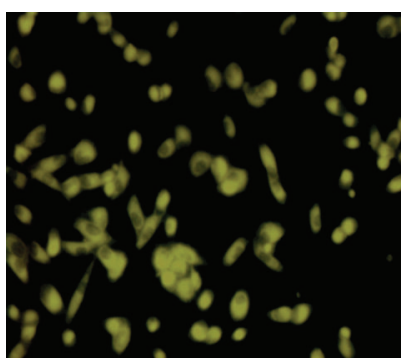

(d)

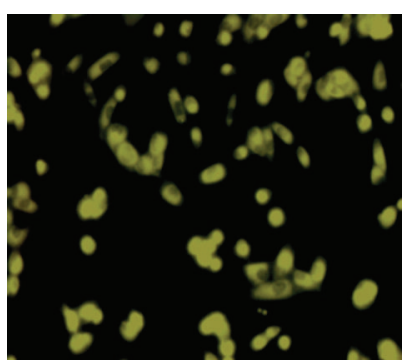

(h)

FIGURE 5: Fluorescence micrographs of $\mathrm{DiOC}_{5}(3)$ (membrane) stained MG63 osteoblast-like cells grown on a plasma polymer film coated onto flat silicon $(\mathrm{a}-\mathrm{d})$ and porous silicon $(\mathrm{e}-\mathrm{h})$. Images were recorded after $4 \mathrm{~h}$ of incubation with $7.7 \times 10^{4}$ cells $/ \mathrm{mL}$. Distances from the hydrocarbon end were $1 \mathrm{~mm}(\mathrm{a}+\mathrm{e}), 10 \mathrm{~mm}(\mathrm{~b}+\mathrm{f}) 11 \mathrm{~mm}(\mathrm{c}+\mathrm{g})$, and $13 \mathrm{~mm}(\mathrm{~d}+\mathrm{h})$. Scale bar $=100 \mu \mathrm{m}$.

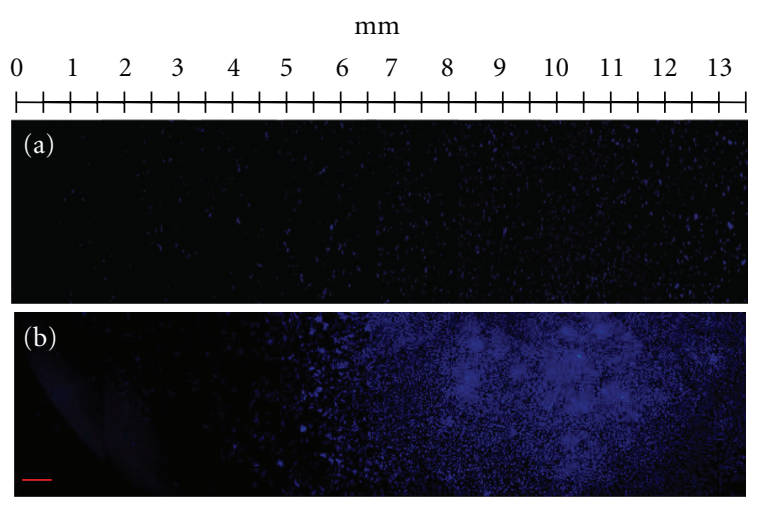

FIGURE 6: Fluorescence micrograph of Hoechst 33342 stained MG63 osteoblast-like cells on plasma polymer chemical gradients on flat silicon (a) and porous silicon (b). Images were recorded after $24 \mathrm{~h}$ of incubation with $7.7 \times 10^{4} \mathrm{cells} / \mathrm{mL}$ and subsequent washing to remove loosely bound cells. Scale bar $=500 \mu \mathrm{m}$. 
[30]. Pores were produced ranging from $5 \mathrm{~nm}$ up to $3 \mu \mathrm{m}$ in a continuous gradient, and following culturing, differences in cell morphology and density were observed. For neuroblastoma cells, a minimum in the cell density and spreading was observed for pores around $100 \mathrm{~nm}$, while $1-3 \mu \mathrm{m}$ pores showed a modest increase in cell spreading compared to flat silicon. These results demonstrate the utility of this method to quickly and simply study the effect of nanotopography on cell behaviour.

4.2. Chemistry. Surface chemical gradients of plasma polymers have also been utilised in previous studies to measure cell behaviour. For example, the surface density of carboxylic acid groups has been used to control the ability of mouse embryonic stem cells to attach to, and spread on, plasma-polymer-coated glass coverslips [31]. It was found that increasing the $\mathrm{COOH}$ surface concentration resulted in greater cell attachment, but the pluripotency of the cells, the potential of a stem cell to differentiate into different cell types, was diminished if the cells were able to spread beyond $140 \mu \mathrm{m}^{2}$.

Cellular attachment of osteoblast cells has also been shown to be extremely sensitive to even small changes in the concentration of negatively charged carboxylic acid groups on substrates, probably due to amphoteric interactions between the polymer chains on the surface and the cell membrane [32]. Daw et al. [14] utilised chemical gradients to measure the effect of carboxylic acid surface functionality on the attachment of osteoblast-like cells. Their study showed cell attachment increased by approximately $200 \%$ with a surface carboxylic acid concentration of just $0.5 \%$. A maximum level in cell attachment was observed at a surface concentration of $\sim 3 \%$ carboxylic acid groups, after which the number of attached cells decreased and returned to "pure hydrocarbon" baseline levels at $\sim 5 \%$. This is in excellent agreement with results presented here, which show a maximum level of cell attachment at a surface concentration of $\sim 2-3 \%$ carboxylic acid groups.

4.3. Potential for $2 D$ Gradients. As discussed above, both surface chemistry and topography have been independently shown to influence cell behaviour and interactions. Gradients of surface chemistry and topography have separately been used to measure their effect on cells in a one-step process. The results reported here, open the possibility of developing a 2D gradient of topography and surface chemistry, with the gradients oriented orthogonally to each other $[33,34]$. It should be noted that the topographical features fabricated here and in other studies $[7,12,30]$ consist of pits or holes. Another approach is to use a chemical gradient to adhere nanoparticles to a surface in a gradient fashion [16]. These nanoparticle density gradients could then be coated with a second chemical gradient to produce a similar $2 \mathrm{D}$ gradient, but with "pillars" rather than holes. This method may be advantageous as the size of the topographical features can be controlled by selecting the size of the nanoparticles. Such surfaces could be used as a method of screening osteoblast cells for bone graft procedures.

\section{Conclusions}

This study has shown that both surface chemistry and surface topography affect the adhesion and spreading of osteoblastlike cells. A greater degree of cell spreading was observed on surfaces with nanoscale pores compared to flat surfaces. Also, surfaces with a surface concentration of $2-3 \%$ carboxylic acid groups were shown to be optimal for cell adhesion and spreading. The use of gradient materials here has demonstrated the possibility of high-throughput screening of mammalian cells interacting with biomaterial surfaces, which is critically relevant to the effort of developing new generation bone-tissue engineering scaffolds. Therefore, plasma polymerised functional chemical gradients on porous silicon substrates show great promise as high-throughput diagnostic tools for analysis of cell and biomaterial interactions.

\section{References}

[1] B. Stevens, Y. Yang, A. Mohandas, B. Stucker, and K. T. Nguyen, "A review of materials, fabrication methods, and strategies used to enhance bone regeneration in engineered bone tissues," Journal of Biomedical Materials Research B, vol. 85, no. 2, pp. 573-582, 2008.

[2] S. D. Glassman, L. Y. Carreon, M. J. Campbell et al., "The perioperative cost of Infuse bone graft in posterolateral lumbar spine fusion," Spine Journal, vol. 8, no. 3, pp. 443-448, 2008.

[3] C. Laurencin, Y. Khan, and S. F. El-Amin, "Bone graft substitutes," Expert Review of Medical Devices, vol. 3, no. 1, pp. 49-57, 2006.

[4] P. Linez-Bataillon, F. Monchau, M. Bigerelle, and H. F. Hildebrand, "In vitro MC3T3 osteoblast adhesion with respect to surface roughness of Ti6Al4V substrates," Biomolecular Engineering, vol. 19, no. 2-6, pp. 133-141, 2002.

[5] L. A. Cyster, K. G. Parker, T. L. Parker, and D. M. Grant, "The effect of surface chemistry and nanotopography of titanium nitride (TiN) films on primary hippocampal neurones," Biomaterials, vol. 25, no. 1, pp. 97-107, 2004.

[6] Y. F. Chou, W. Huang, J. C. Y. Dunn, T. A. Miller, and B. M. $\mathrm{Wu}$, "The effect of biomimetic apatite structure on osteoblast viability, proliferation, and gene expression," Biomaterials, vol. 26, no. 3, pp. 285-295, 2005.

[7] J. Y. Lim, A. D. Dreiss, Z. Zhou et al., "The regulation of integrin-mediated osteoblast focal adhesion and focal adhesion kinase expression by nanoscale topography," Biomaterials, vol. 28, no. 10, pp. 1787-1797, 2007.

[8] T. P. Kunzler, T. Drobek, M. Schuler, and N. D. Spencer, "Systematic study of osteoblast and fibroblast response to roughness by means of surface-morphology gradients," Biomaterials, vol. 28, no. 13, pp. 2175-2182, 2007.

[9] E. K. F. Yim, E. M. Darling, K. Kulangara, F. Guilak, and K. W. Leong, "Nanotopography-induced changes in focal adhesions, cytoskeletal organization, and mechanical properties of human mesenchymal stem cells," Biomaterials, vol. 31, no. 6, pp. 1299-1306, 2010.

[10] T. P. Kunzler, C. Huwiler, T. Drobek, J. Vörös, and N. D. Spencer, "Systematic study of osteoblast response to nanotopography by means of nanoparticle-density gradients," Biomaterials, vol. 28, no. 33, pp. 5000-5006, 2007.

[11] G. Mendonça, D. B. S. Mendonça, F. J. L. Aragão, and L. F. Cooper, "Advancing dental implant surface technology—from 
micron- to nanotopography," Biomaterials, vol. 29, no. 28, pp. 3822-3835, 2008.

[12] R. J. McMurray, N. Gadegaard, P. M. Tsimbouri et al., "Nanoscale surfaces for the long-term maintenance of mesenchymal stem cell phenotype and multipotency," Nature Materials, vol. 10, no. 8, pp. 637-644, 2011.

[13] M. M. Stevens and J. H. George, "Exploring and engineering the cell surface interface," Science, vol. 310, no. 5751, pp. 1135$1138,2005$.

[14] R. Daw, S. Candan, A. J. Beck et al., "Plasma copolymer surfaces of acrylic acid/1,7 octadiene: surface characterisation and the attachment of ROS 17/2.8 osteoblast-like cells," Biomaterials, vol. 19, no. 19, pp. 1717-1725, 1998.

[15] M. Arnold, V. C. Hirschfeld-Warneken, T. Lohmüller et al., "Induction of cell polarization and migration by a gradient of nanoscale variations in adhesive ligand spacing," Nano Letters, vol. 8, no. 7, pp. 2063-2069, 2008.

[16] R. V. Goreham, R. D. Short, and K. Vasilev, "Method for the generation of surface-bound nanoparticle density gradients," Journal of Physical Chemistry C, vol. 115, no. 8, pp. 3429-3433, 2011.

[17] T. Willliams and M. W. Hayes, "Polymerization in a glow discharge,” Nature, vol. 209, no. 5025, pp. 769-773, 1966.

[18] H. Yasuda, Plasma Polymerisation, Academic Press, New York, NY, USA, 1985.

[19] M. A. Lieberman and A. J. Lichtenberg, Principles of Plasma Discharges and Materials Processing, John Wiley and Sons, Chicester, UK, 1994.

[20] H. Biederman, Plasma Polymer Films, Imperial College Press, London, UK, 2004.

[21] A. J. Beck, F. R. Jones, and R. D. Short, "Plasma copolymerization as a route to the fabrication of new surfaces with controlled amounts of specific chemical functionality," Polymer, vol. 37, no. 24, pp. 5537-5539, 1996.

[22] J. J. A. Barry, D. Howard, K. M. Shakesheff, S. M. Howdle, and M. R. Alexander, "Using a core-sheath distribution of surface chemistry through 3D tissue engineering scaffolds to control cell ingress," Advanced Materials, vol. 18, no. 11, pp. 14061410, 2006.

[23] J. Cho, F. S. Denes, and R. B. Timmons, "Plasma processing approach to molecular surface tailoring of nanoparticles: improved photocatalytic activity of $\mathrm{TiO}_{2}$," Chemistry of Materials, vol. 18, no. 13, pp. 2989-2996, 2006.

[24] J. D. Whittle, D. Barton, M. R. Alexander, and R. D. Short, "A method for the deposition of controllable chemical gradients," Chemical Communications, vol. 9, no. 14, pp. 1766-1767, 2003.

[25] K. Vasilev, Z. Poh, K. Kant, J. Chan, A. Michelmore, and D. Losic, "Tailoring the surface functionalities of titania nanotube arrays," Biomaterials, vol. 31, no. 3, pp. 532-540, 2010.

[26] L. R. Clements, P.-Y. Wang, F. Harding, W.-B. Tsai, H. Thissen, and N. H. Voelcker, "Mesenchymal stem cell attachment to peptide density gradients on porous silicon generated by electrografting," Physica Status Solidi A, vol. 208, no. 6, pp. 1440-1445, 2011.

[27] G. Beamson and D. Briggs, High Resolution XPS of Organic Polymers: The Scienta ESCA300 Database, John Wiley and Sons, Chicester, UK, 1992.

[28] D. Briggs, Surface Analysis of Polymers by XPS and Static SIMS, Cambridge Univeristy Press, Cambridge, UK, 1998.

[29] J. Y. Suh, B. C. Jang, X. Zhu, J. L. Ong, and K. Kim, "Effect of hydrothermally treated anodic oxide films on osteoblast attachment and proliferation," Biomaterials, vol. 24, no. 2, pp. 347-355, 2003.
[30] Y. L. Khung, G. Barritt, and N. H. Voelcker, "Using continuous porous silicon gradients to study the influence of surface topography on the behaviour of neuroblastoma cells," Experimental Cell Research, vol. 314, no. 4, pp. 789-800, 2008.

[31] N. Wells, M. A. Baxter, J. E. Turnbull et al., "The geometric control of E14 and R1 mouse embryonic stem cell pluripotency by plasma polymer surface chemical gradients," Biomaterials, vol. 30, no. 6, pp. 1066-1070, 2009.

[32] N. G. Maroudas, "Adhesion and spreading of cells on charged surfaces," Journal of Theoretical Biology, vol. 49, no. 2, pp. 417424, 1975.

[33] J. Zhang and Y. Han, "A topography/chemical composition gradient polystyrene surface: toward the investigation of the relationship between surface wettability and surface structure and chemical composition," Langmuir, vol. 24, no. 3, pp. 796801, 2008.

[34] J. Yang, F. R. A. J. Rose, N. Gadegaard, and M. R. Alexander, "A high-throughput assay of cell-surface interactions using topographical and chemical gradients," Advanced Materials, vol. 21, no. 3, pp. 300-304, 2009. 

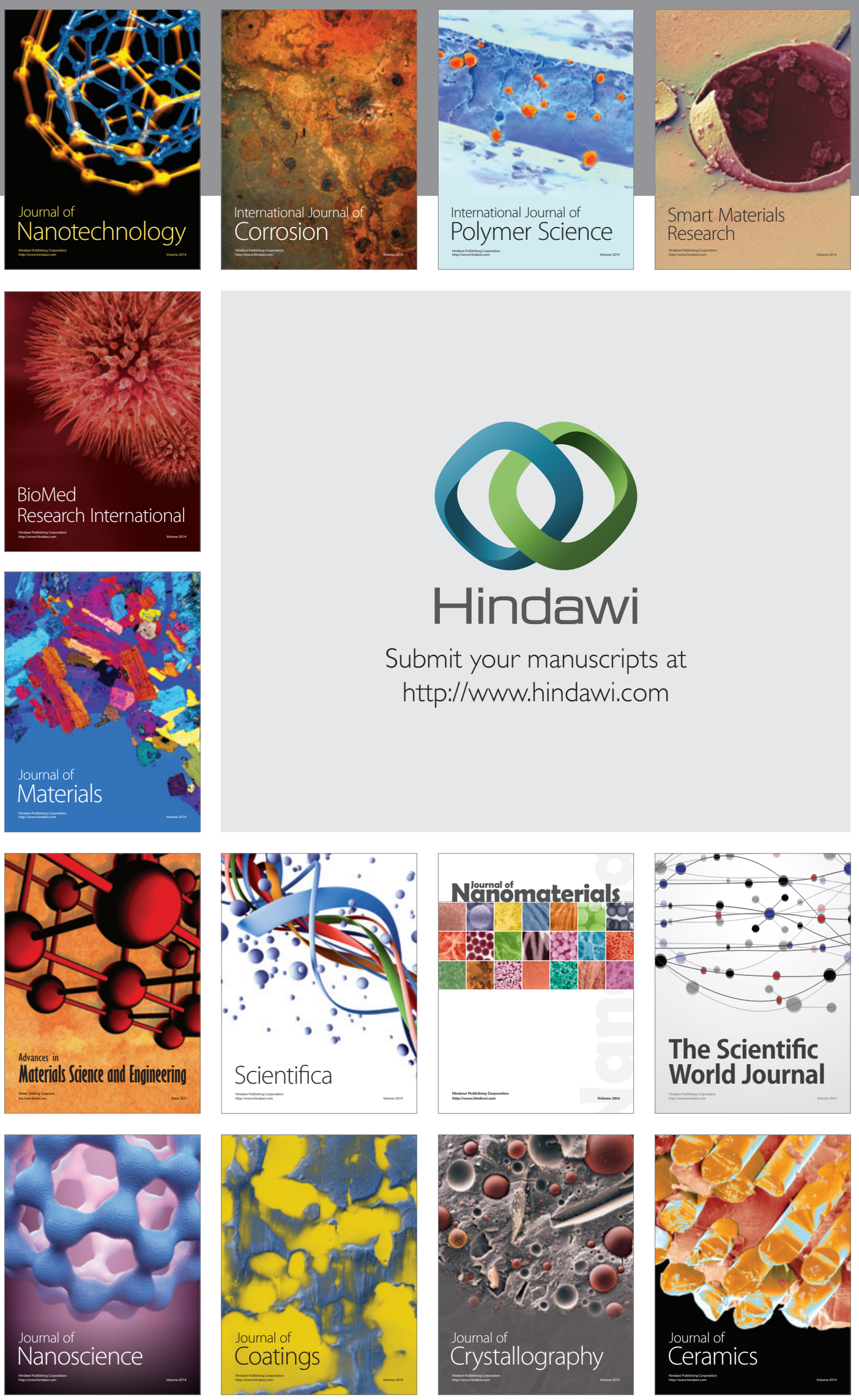

The Scientific World Journal

Submit your manuscripts at

http://www.hindawi.com

\section{World Journal}

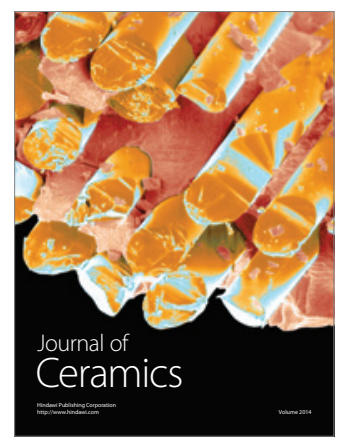

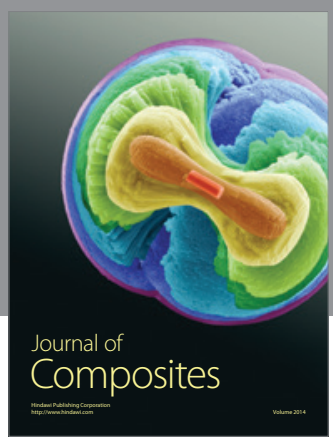
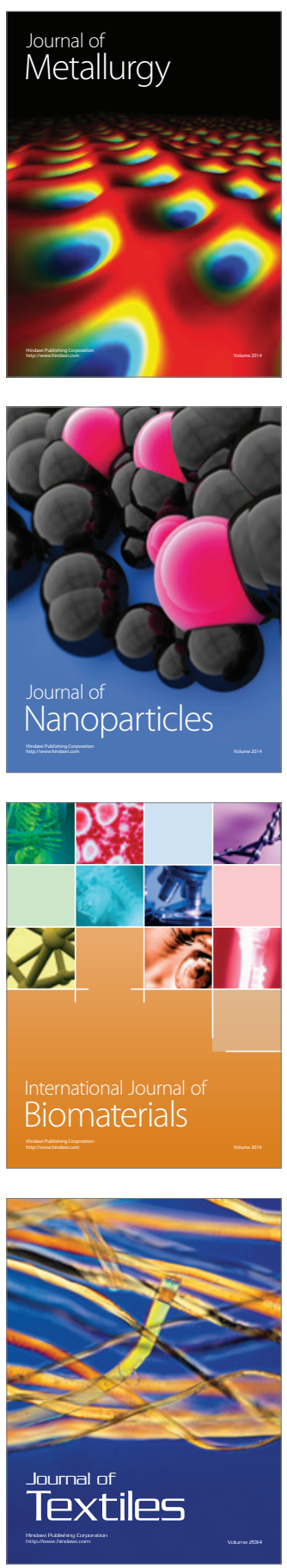